\title{
Analysis of the collection of Coriandrum sativum $L$. as a source of high-potential samples for selection research
}

\author{
S.I. Krivda ${ }^{1}$, N.V. Nevkrytaya ${ }^{1}$, V.S. Pashtetsky ${ }^{1,2}$, S.S. Babanina ${ }^{1}$, O.B. Skipor ${ }^{1}$, \\ N.S. Krivchik ${ }^{1}$, A.V. Skiba ${ }^{1}$ \\ ${ }^{1}$ Research Institute of Agriculture of Crimea \\ ${ }^{2}$ Ural State Agrarian University \\ Russian Federation
}

Received: March 24, 2020. Revised: May 28, 2020. Accepted: June 11, 2020. Published: June 19, 2020.

\begin{abstract}
One way for conservation the genetic diversity of plants is to make collections of the samples of different species. Specific collections of species that are used as food, medicinal, industrial crops are usually created in institutions where the studies of their useful properties, selection and seed production are conducted. One of the most common essential oil crops is Coriandrum sativum $L$. The main direction for coriander selection is the development of varieties with high yield and high content of essential oil. The goal of this research was to study the coriander collection in the conditions of the Crimean Foothills as valuable source material for selection. This collection includes 159 samples from 30 regions obtained from the Federal Research Center "Vavilov All-Russian Institute of Plant Genetic Resources" and 5 varieties from the Research Institute of Agriculture of Crimea (RIAC). Analysis of this collection by a set of parameters was carried out in 2017-2019 in accordance with the techniques for essential oil crops. The study was conducted at the experimental site of the RIAC located in Krymskaya Roza village (Belogorsky district, Crimea). The climate of this region is moderately continental. This territory belongs to one of the five agroclimatic regions - upper foothill, warm, not humid enough; to the northern subarea with moderately mild winters. High variability of the collection for the most significant productivity parameters was established. So, coefficients of variation for yield of fruits and for the content of essential oil are 37.2 and $51.3 \%$, respectively. This indicates high potential of further work with this collection in order to develop valuable selection material. Evaluation of the results of studying this collection in years with different weather conditions made it possible to select 26 samples according to the set of parameters or to specific valuable features that were high-potential for further selection.
\end{abstract}

Keywords - Collection, coriander, productivity parameters, variability.

\section{INTRODUCTION}

$\mathrm{O}$ $\mathrm{NE}$ way for conservation the genetic diversity of plants is to make collections of the samples of different species [1], [2]. However in Botanical gardens of the world include, first of all, flora of a particular region and of regions with similar climatic conditions. The most widely represented species are those used as ornamental, or for landscape gardening in settlements or making landscape compositions. Specific collections of species that are used as food, medicinal, industrial crops are usually created in institutions where the studies of their useful properties, selection and seed production are conducted [3], [4]. Federal Research Center "Vavilov All-Russian Institute of Plant Genetic Resources" (VIR) is the main center in the Russian Federation that maintains species diversity of plants from different regions of the world and provides for the needs of a number of institutions and organizations in source material.

Coriandrum sativum $\mathrm{L}$. is one of the most widespread essential oil crops in the world. It is widely used due to its spicy aromatic properties. Coriander fruits and essential oil is used in perfumery, cosmetics, pharmaceutical, alcoholic beverage, and food industries [5] - [8]. Anti-inflammatory, antimicrobial, antibiotic and other valuable properties provided by the valuable components in coriander essential oil make it usable in medicine [9]-[12]. Coriander can be recommended as a hepatoprotector in the treatment of toxic hepatitis [13], [14]. Coriander is used in veterinary medicine, as an ingredient of Gastroacid feed phytoadditive for the prevention of gastrointestinal pathologies in calves [15]. Coriander essential oil has a sedative effect on newborn chickens [16]. Coriander is also a good honey plant [17].

The content of essential oil in coriander fruits varies from $0.03 \%$ to $3.0 \%$. It includes more than 20 components; the main of them is linalool (60-80\%). In addition to it, there are geraniol (3-7\%), linalyl acetate (3-5\%), geranyl acetate (3-7\%), limonene (3\%), citronelol, terpineol, nerol, etc. [18]-[21].

According to N.A. Lvov et al. [22], C. sativum has nine basic ecological and geographical groups: European, Asia Minor, 
Afghan, African, Indian, Abyssinian, Transcaucasian, Abkhaz, and Western Chinese. Differences between specified groups concern a number of morpho-biological parameters and economic characteristics: plant height, type of leaf arrangement, color of flowers, height of the lower umbel, degree of leaf blade lobing, content of essential oil in fruits, and yield.

In Russia, coriander occupies the great part of areas under essential oil crops. High-quality essential oil is produced from its fruits with the high content of the main component - linalool (more than 70\%). Demand for coriander in the world market is high, however, it significantly depends on the weather conditions of the year, and, accordingly, on the crop yield in the main regions that are suppliers of this product [23], [24].

C. sativum is a highly profitable crop; its domestic varieties are in demand by agricultural producers. Therefore, the main direction of its selection is the cultivation of new adaptive varieties with increased fruit yield and high content of highquality essential oil. The source of high-potential genotypes and donors of valuable traits are the collections of coriander gene pool [25], [26]. Analysis of collection samples allows determining their variability by basic morpho-biological and productivity parameters and clarifying dependence of these parameters on biotic and abiotic factors. Moreover, information on the nature of the manifestation of the main indicators in specific soil and climatic conditions, depending on the emerging hydrothermal conditions, is of particular value. Result of this analysis is defining samples with high potential as donors of valuable traits for further selection [27], [28]. The analysis of different coriander genotypes performed by Indian researchers showed their high variability in a number of basic parameters that have an effect on yield. Studying the nature of the heritability of these parameters allowed concluding that selective breeding work has high potential in terms of increasing the productivity of this culture [29], [30]. Analysis of the essential oil of coriander samples from five regions of Northern India showed high diversity in the content of its components what indicates the possibility of using this diversity for commercial purposes based on requirements for aroma, taste and pharmaceutical value [31].

Collection material of $C$. sativum and development of varieties on its base has been carried out in Crimea for decades [32]. Many varieties of this culture were developed by researchers at the All-Union Research Institute of Essential Oil Crops (later the Institute of Essential Oils and Medicinal Plants of the National Academy of Agricultural Sciences of Ukraine). Currently, collection of $C$. sativum is maintained, enlarged and studied - in order to select high-potential material for selective breeding research - at the Research Institute of Agriculture of Crimea which included the Institute of Essential Oils and Medicinal Plants.

\section{MATERIALS AND METHODS}

In 2017-2019, Department of Essential Oil and Medicinal Crops of the Research Institute of Agriculture of Crimea conducted a study on a complex of morpho-biological and economic characteristics of the collection of $C$. sativum in the amount of 164 samples from 30 regions (Table 1).

Table 1. Samples of Coriandrum sativum collection

\begin{tabular}{cccccc}
\hline Region & Number of samples & Region & $\begin{array}{c}\text { Number of } \\
\text { samples }\end{array}$ & Region & Number of samples \\
\hline Abkhazia & 19 & Kazakhstan & 7 & Romania & 1 \\
\hline Adjara & 3 & Kyrgyzstan & 1 & USA & 1 \\
\hline Azerbaijan & 33 & China & 3 & Somalia & 2 \\
\hline Armenia & 11 & Korea & 1 & Tajikistan & 1 \\
\hline Belarus & 1 & Crimea & 5 & Turkmenistan & 1 \\
\hline Georgia & 35 & Mongolia & 1 & Uzbekistan & 10 \\
\hline Dagestan & 3 & Nagorno-Karabakh & 2 & Ukraine & Ethiopia \\
\hline Transcaucasia & 1 & Oman & 1 & Yugoslavia & 1 \\
\hline India & 1 & Poland & 1 & 11 & 164 \\
\hline Iran & 1 & Russia & &
\end{tabular}

Experimental site of the Department of Essential Oil and

All samples, with the exception of 5 varieties of the Research Institute of Agriculture of Crimea (Ranniy, Yantar, Nektar, Medun, and Silach), were obtained in 2016 from the Federal Research Center "Vavilov All-Russian Institute of Plant Genetic Resources" in order to enlarge the collection of the institute. Studied collection includes, first of all, samples from the Caucasus Region. This selection is based on the results of previous studies that have shown the effectiveness of samples from this region - both donors of high productivity and donors of resistance - to the most dangerous coriander disease, ramulariosis [33].
Medicinal Crops is located in the foothill zone of the Crimea, in its eastern part (Krymskaya Roza village, Belogorsky district). Climate of this region is moderately continental. This

territory belongs to one of the five agroclimatic regions - the upper foothill, warm, not humid enough; to the northern subarea with moderately mild winters [34]. Average annual temperature is $10^{\circ} \mathrm{C}$. Period with positive air temperature lasts for 292 days a year. Average temperature of the warmest month, July, is $+21^{\circ} \mathrm{C}$; that of the coldest month, January, is $0.8^{0} \mathrm{C}$. Maximum possible temperature increase in summer is up to $40^{\circ} \mathrm{C}$ and minimum decrease in winter - down to -30- 
$35^{\circ} \mathrm{C}$. Average long-term amount of precipitation is $498 \mathrm{~mm}$, during vegetation- $280 \mathrm{~mm}$. Average annual air humidity is $70 \%$, hydrothermal coefficient is 0.91 what indicates the arid nature of weather conditions. Soil at the study site is southern carbonate, heavy loamy chernozem $(\mathrm{pH}-7.0-7.2$, humus content in arable layer $-2.7-3.0 \%$, total nitrogen $0.12 \%$, phosphorus $0.10 \%$, potassium $1.0 \%$ ).

Samples were placed on plots $1 \mathrm{~m}$ long with space between rows of $0.6 \mathrm{~m}$. Plot area was $0.6 \mathrm{~m} 2$. Replication was twofold. Sowing was performed in optimal time, i.e. in the third decade of March.

Analysis of collection samples was carried out according to the developed methods for the following parameters:

- phenological - period from seedlings to flowering, from flowering to ripening, total duration of vegetation period [35]. This information is important when choosing samples to create varieties that differ in early maturity;

- morpho-biological -height of plant, height of the lower umbel, the number of fruits in an umbel of the $1^{\text {st }}$ order, weight of 1,000 fruits [36]. These indicators are indirect in assessing the potential yield of the source material, as well as assessing its prospects in creating varieties convenient for mechanized harvesting;

-productivity - yield per plot [36]. The information is needed when selecting source material to create highly productive varieties;

- biochemical - content of essential oil in fruits [37]. The indicator is most important for the selection of essential oil plants cultivated in order to obtain essential oil.

Obtained data were statistically processed using Microsoft Office Excel 2010 software package [38]-[40].

\section{RESULTS}

Weather conditions during the years of research (2017-2019) were contrasting (Fig. 1.2).

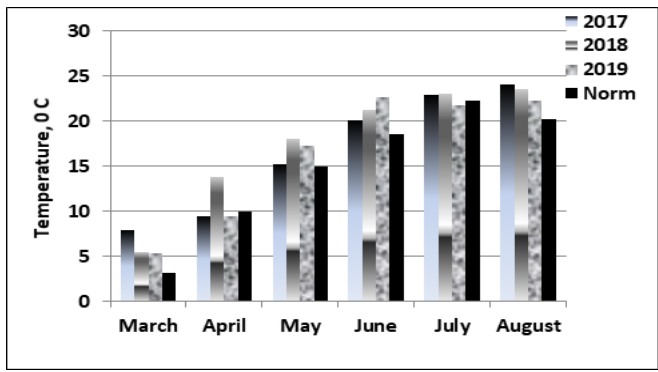

Figure. 1 Average monthly air temperature during the period of active vegetation, 2017-2019.

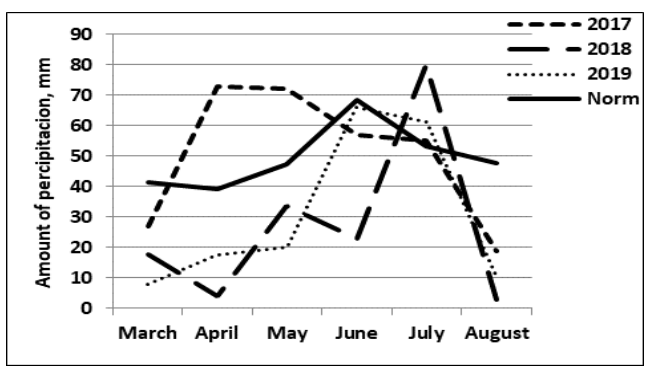

Figure 2. Average monthly precipitation during the period of active vegetation, 2017-2019.

In 2017 they were generally favorable. However, heavy precipitation in April-June caused the development of ramulariosis that resulted in decreased productivity. The next year, 2018, was hot and extremely arid. Seedlings partially died

Plants on plots were sparse and uneven in development, which may indicate a high genotypic heterogeneity within the sample and, accordingly, a different reaction of genotypes to extreme conditions. At the same time, the high temperature regime, which is negative for the formation of a full-fledged crop, is favorable for the oil-forming process, and has contributed to an increase in the content of essential oil in fruits. Weather conditions in 2019 were average: with arid spring, hot June, and enough rainfall in the $2^{\text {nd }}$ half of the month. Large amount of precipitation fell in early July but temperature was slightly below normal.

Phenological observations showed that the first sprouts of coriander appear, on average, on days 21-25 after sowing. However, depending on the conditions, it may be delayed up to 55 days for certain samples - as it was observed in 2019. Total vegetation period of collection samples from full seedlings to fruit ripening, on average over three years, ranged from 69 to 87 days. According to this parameter, all samples were conventionally divided into three groups: early ripening, up to 75 days - 46 samples $(28.0 \%$ of the total number of samples studied), mid-ripening, 76-80 days - the largest group including 84 samples (51.2\%), and late ripening, 81 and more days - 34 samples $(20.7 \%)$. Ranniy and Medun varieties were included in early ripening group (71 and 73 days, respectively), Yantar and Nectar - in mid-ripening group (on average, 79 and 80 days, respectively), and Silach variety proved to be late-ripening (on average, 84 days).

Duration of vegetation period varied depending on annual conditions. It was the shortest in the extremely arid and hot conditions of 2018 - from 50 to 83 days. The greatest stability in the duration of vegetation period regardless of weather conditions was shown by 17 samples. Fluctuation of this parameter ranged from 1 to 7 days over the years. The selection and use of samples that are stable over the duration of the growing season is especially important when creating varieties that differ in early maturity, with forecast harvest terms.

A comparative study of collection samples by the main economically valuable indicators is necessary to assess the potential of the collection, its prospects for selection. In this case, the source material is analyzed, both for the complex and for individual characteristics that are important for breeding varieties with specified parameters. Basic economic characteristics of analyzed collection samples are given in Table 2.

Table 2. Economic characteristics of collection samples of Coriandrum sativum, 2017-2019. 


\begin{tabular}{lcccccc}
\hline Parameter & $\begin{array}{c}\text { Plant height, } \\
\mathrm{cm}\end{array}$ & $\begin{array}{c}\text { Number of fruits in } \\
\text { umbels of the } \\
1^{\text {st }} \text { order, pcs. }\end{array}$ & $\begin{array}{c}\text { Weight of } \\
1,000 \text { fruits, }\end{array}$ & $\begin{array}{c}\text { Fruit yield, } \\
\text { g per plot } \\
\left(0.6 \mathrm{~m}^{2}\right)\end{array}$ & $\begin{array}{c}\text { Weight content of } \\
\text { essential oil in fruits, } \\
\%\end{array}$ & $\begin{array}{c}\text { Yield of essential } \\
\text { oil, g per plot } \\
\left(0.6 \mathrm{~m}^{2}\right)\end{array}$ \\
\hline $\begin{array}{l}\text { Average value } \\
\text { in collection }\end{array}$ & $54.1 \pm 0.4$ & $31.0 \pm 0.4$ & $4.3 \pm 0.1$ & $33.5 \pm 1.0$ & $1.19 \pm 0.05$ & $0.40 \pm 0.02$ \\
\hline Range & $31.7-68.4$ & $14.4-42.8$ & $2.6-9.1$ & $8.1-73.9$ & $0.53-3.62$ & $0.07-1.23$ \\
\hline $\begin{array}{l}\text { Coefficient of } \\
\text { variation (V), } \\
\%\end{array}$ & 10.4 & 18.1 & 23.1 & 37.2 & 51.3 & 60.0 \\
\hline
\end{tabular}

On average, the height of plants of analyzed samples was in the range from 32 to $68 \mathrm{~cm}$ during the years of research. The average height of plants of the Institute varied from 47 to 60 $\mathrm{cm}$. In 2017 with the most favorable combination of temperature and precipitation, the plants of all samples reached the maximum height over the years of study- 58-96 $\mathrm{cm}$, including that of varieties $-76-85 \mathrm{~cm}$. In extremely dry and hot conditions of 2018, plants were significantly less. Their height for the samples was on average $18-51 \mathrm{~cm}$. The average height of plant varieties was $37-42 \mathrm{~cm}$. Weather conditions in 2019 were more favorable compared to 2018. Accordingly, the average height of plants of all samples was slightly higher $-29-64 \mathrm{~cm}$, and that of varieties $-50-55 \mathrm{~cm}$. Variation of this parameter is insignificant and the smallest one among all analyzed parameters $(\mathrm{V}=10.4 \%)$. The height of plants obviously depends mainly on weather conditions during their growth and is less significantly on genotype.

The number of fruits in first-order umbels (the main structural component of the crop) also depends on temperature and humidity during their formation. The range of variability of this parameter in collection samples was quite large - from 14 to 42 pieces, on average, over three years. However, this parameter for each sample was less dependent on annual conditions. Collection variability for this parameter was average, coefficient of variation amounted to $18.1 \%$.

The weight of 1,000 fruits varied quite largely in this collection - on average, over three years, from 2.6 to $9.1 \mathrm{~g}$. Coefficient of variation amounted to $23.1 \%$. All samples were conventionally divided into three groups: small-fruited (less than 4 g) - 65 samples (39.6\%), medium-fruited (4-6 g) - 91 samples $(55.5 \%)$, and large-fruited (more than $6.0 \mathrm{~g}$ ) -8 samples (4.9\%). All varieties of the Institute were classified as medium-fruited (on average, 4.1-4.2 g), except for Medun with small fruits (on average, $3.0 \mathrm{~g}$ ). The weight of fruits depends on both genetic determination and the combination of temperature and humidity during their formation and development. The smallest fruits were formed in extremely arid and hot conditions in 2018. Samples that were fairly stable by this criterion and remained in one size group for all three years were defined. Most of such samples belonged to the small-fruited group - 25 samples $(38.5 \%$ of the number of samples in the group). In medium-fruited group, the percentage of stable samples by this parameter was significantly lower $-27.5 \%$ (25 samples). 2 samples out of 8 large-fruited ones $(25.0 \%)$ with average weight of 1,000 fruits about $9 \mathrm{~g}$ stably maintained this parameter value.

The correlation between large size of fruits (weight of $1,000$ fruits $)$ and content of essential oil was low $(r=0.26)$ but spice producers found large seeds more attractive. The presence of samples stably forming large fruits allows us to consider them as source material for creating varieties of this direction of use.

A wide range of variability $(\mathrm{V}=37.2 \%)$ in the yield of fruits per plot was registered for studied samples - on average, according to three-year data it amounted from 8.1 to $73.9 \mathrm{~g}$.

The group of low yielders (up to $30 \mathrm{~g} / \mathrm{plot}$ ) included 69 samples $(42.0 \%)$; the group with medium yield (30-45 g/plot) - 67 samples (40.9\%) including Nektar, Yantar and Ranniy varieties. The group of $28(17.1 \%)$ the most productive samples (more than $45 \mathrm{~g} / \mathrm{plot}$ ) attracted the most interest.

Analysis of the weight content of essential oil in the fruits of collection samples showed a wide variability, on average, from 0.53 to $3.62 \%$ for absolutely dry weight over three years. Based on their value for selection, all samples were divided into three groups:

- low oil, with the weight content of essential oil less than $2.0 \%-134$ samples $(81.7 \%)$;

- medium oil, with the weight content of essential oil of 2.0$2.5 \%-14$ samples $(8.5 \%)$;

- high oil, with the weight content of essential oil of more than $2.5 \%$ - 16 samples $(9.8 \%)$. This group includes all five varieties of the Institute.

About 50 samples showed high stability for this parameter over years of study despite the significant differences in weather conditions. For most part of the other samples, the most favorable for the accumulation of essential oil conditions were in 2019 that was characterized by an abundance of rain during the period of fruit formation. The highest content of essential oil in fruits in the main part of the samples was registered in the driest and hottest 2018. Optimal conditions for the accumulation of essential oil in fruits are high air temperature and relatively low humidity during flowering and fruit formation. However, these parameters should not reach extreme values. Significant variability in the content of essential oil within the collection $(\mathrm{V}=51.3 \%)$ indicates its high genotypic dependence.

The presence in the collection of samples that exceed the created varieties in terms of the content of essential oil in the fruits indicates the prospect of selection work aimed at increasing this indicator.

Average yield of essential oil from the collection samples over three years varied largely - from 0.07 to $1.23 \mathrm{~g}$ per plot $(0.6 \mathrm{~m} 2)$. This parameter is the result of two ones-fruit yield and weight content of essential oil in them. It was the largest in 2017 due to the high yield of fruits that was formed under the 
optimal combination of temperature and precipitation during the period of active vegetation. In order to define highpotential samples for selection, the collection was conventionally divided by this parameter into three groups that differ significantly in their quantitative composition:

- low oil yield, up to $0.5 \mathrm{~g} / \mathrm{plot}-118$ (72.0\%) samples;

- medium oil yield, 0.51-0.7 g/plot- 26 (15.8\%) samples;

- high oil yield, more than $0.7 \mathrm{~g} / \mathrm{plot}-20$ (12.2\%) samples including Yantar, Silach and Nektar varieties.

High variability of this collection for the most significant productivity parameters indicates high potential of further work with it in order to obtain valuable selective breeding material for developing highly productive varieties of $C$. sativum.

Based on the results of a three-year study of coriander collection, in comparison with the Institute's varieties, there were defined high potential samples with high values for the complex or specific economic characteristics. Main parameters for selection included yield of fruits per plot, weight content of essential oil in them, and yield of essential oil per unit area. A total of 26 best samples were selected with average fruit yield of $12.0 \pm 3.8$ to $73.9 \pm 32.4 \mathrm{~g}$ per plot, weight content of essential oil from $0.97 \pm 0.02$ to $3.49 \pm 0.08 \%$ (for absolutely dry fruit mass), and yield of essential oil from $0.56 \pm 0.24$ to $1.23 \pm 0.60 \mathrm{~g}$ per plot. Average values for the varieties of the Federal State Budgetary Research Institution "Crimean Agricultural Research Institute" were the following: yield of fruits $-28.8 \pm 10.4-33.0 \pm 16.2 \mathrm{~g}$ per plot, weight content of essential oil $-2.99 \pm 0.49-3.26 \pm 0.20 \%$, and yield of essential oil $-0.70 \pm 0.55-0.90 \pm 0.45$ g per plot. Selected samples will be included in further selective breeding studies.

The authors are grateful to the staff of the Federal Research Center "Vavilov All-Russian Institute of Plant Genetic Resources" for the provided seeds of collection samples of $C$. sativum.

\section{CONCLUSIONS}

1.In the conditions of the foothill zone of the Crimea, the Coriandrum sativum L. collection, including 164 samples of different origins, was analyzed by a complex of morphological, biological and economically valuable traits

2.High variability of this collection by the most significant productivity parameters indicates high potential of further work with it in order to develop valuable selective breeding material for the subsequent development of highly productive varieties of $C$. sativum.

3. As a result of studying the collection in years with different weather conditions (2017-2019) by the set of parameters or by specific characteristics, 26 best samples with the following profile were selected for further selection studies: average fruit yield of $12.0 \pm 3.8$ to $73.9 \pm 32.4 \mathrm{~g}$ per plot of $0.6 \mathrm{~m} 2$, weight content of essential oil from $0.97 \pm 0.02$ to $3.49 \pm 0.08 \%$ (for absolutely dry fruit mass), and yield of essential oil from $0.56 \pm 0.24$ to $1.23 \pm 0.60 \mathrm{~g}$ per plot.

4. The results of the study and the obtained characterization of collection samples by the main morphological and biological parameters and productivity indicators will be used to create a reference guide for researchers conducting breeding studies of $C$. sativum and related species of the Apiaceae family, in particular, Anisum vulgare Gaertn and Foeniculum vulgare Mill

\section{References}

[1] R. Mounce, P. Smith, S. Brockington, Ex situ conservation of plant diversity in the world's botanic gardens, Nature Plants, 3, 2017; pp. 795-802 DOI: 10.1038/s41477-0170019-3

[2] K. O'donnell, Sharrock S. botanic gardens complement agricultural gene bank in collecting and conserving plant genetic diversity. Biopreserv Biobank, 16(5), 2018; pp. 384-390 doi: 10.1089/bio.2018.0028

[3] Y. Lee, J. Mun, Y. Jeong, S. Joo, H. Yu, Assembly of a radish core collection for evaluation and preservation of genetic diversity, Hortic. Environ. Biotechnol, 59, 2018, pp. 711-721 doi.org/10.1007/s13580-018-0079-y

[4] B. Schlautman, G. Covarrubias-Pazaran, L. RodriguezBonilla, K. Hummer, N. Basil, T. Smith, J. Zalapa, Genetic diversity and cultivar variants in the NCGR cranberry (Vaccinium macrocarpon Aiton) collection. J Genet, 97, 2018, pp. 1339-1351 doi.org/10.1007/s12041-018-1036-3

[5] V. S. Pashtetsky, N. V. Nevkritaya, Using essential oils in medicine, aromatherapy, veterinary medicine and crop science (review), Taurian Bulletin of Agricultural Science, 1(13), 2018, pp. 18-40 doi: 10.25637 / TVAN2018.01.02

[6] E. A. Woytsekhovskaya, M. A. Chelombitko, Biochemical studies of aromatic plants and fruits fordeveloping food compositions. In collection: Problems of the conservation of biological diversity and using biological resources. Materials of the III International Research and Practical Conference dedicated to the $110^{\text {th }}$ birthday of academician N.V. Smolsky. In 2 parts, 2015, pp. 288-291

[7] Yu. V. Lavrinenko, I. A. Nikolaev, Composition of herbal tea Patent for an invention RU 2700629, 18 SEP 2019, Application No 2018108287 from 06 MAR 2018

[8] E. A. Pisarnitskaya, Wine beverage. Patent for an invention RU 2597966 C1, 20 Sep. 2016. Application No. 2015145223/10 from 21 OCT 2015

[9] K. Singh, R. Rani, P. Bansal, S. Medhe, M. M. Srivastava, Antioxidant activity of essential oil of Coriandrum sativum and standardization of HPTLC method for the estimation of major phytomarkers, Journal of Analytical Chemistry; 70(2), 2015, pp. 220-224 doi: 10.1134/S1061934815020094

[10] A. C. De Melo, M. D. V. Santos, M. F. Carvalho, J. A. Takarashi, V. P. Ferraz, E. A. Chagas, P. C. Chagas, A. A. De Melo Filho, Phytochemical Trial and Bioactivity of the Essential Oil from Coriander Leaves (Coriandrum sativum) on Pathogenic Microorganisms, Chemical engineering transactions, 75, 2019, pp. 403-408 doi: 10.3303/CET1975068

[11] H. Yildiz, Chemical Composition, Antimicrobial and Antioxidant Activities of Essential Oil and Ethanol Extract of Coriandrum sativum L. Leaves from Turkey, 
International Journal of Food Properties, 9(7), 2015, pp. 1593-1603 doi:10.1080/10942912.2015.1092161

[12] A. E. Al-Snafi, A review on chemical constituents and pharmacological activities of Coriandrum sativum, IOSR Journal of Pharmacy, 6(7), 2016, pp. 17-42

[13] Yu. K. Vasilenko, V. V. Davydova, N. O. Gorbatyuk, V. F. Reps, Hepatoprotective and antioxidant properties of extracts fromCoriandrum sativum herb in the setting of toxic liver damage with carbon tetrachloride and ethanol, Modern Science and Innovations, 3(19), 2017, pp. 202-211

[14] V. V. Arakelyan, Yu. K. Vasilenko, A. Yu. Ogurtsov, Structural and metabolic changes caused by alcohol-related liver disease when taking extracts from Coriandrum sativum herb. Fundamental Research; 5-6, 2014, pp. 12621265

[15] N. Suslova, P. Antonenko, N. Makeyeva, O. Strakh, The effectiveness of the comprehensive preventive measures for gastroenteral pathology in calves. Research Bulletin of Veterinary Medicine, 2 (122), 2015, 78-83

[16] M. S. Gastón, M. P. Cid, A. M. Vázquez, M. F. Decarlini, G. I. Demmel, L. I. Rossi, M. L. Aimar, N. A. Salvatierra, Sedative effect of central administration of Coriandrum sativum essential oil and its major component linalool in neonatal chicks. Pharmaceutical Biology, 54 (10), 2016, pp. 1-8 doi: 10.3109/13880209.2015.1137602

[17] A. P. Savin, N. A. Gudimova, Productivity of Coriandrum sativumdepending on the normal parameters and time of sowing. Bulletin of Kostychev Ryazan State Agrotechnological University, 1(29), 2016, pp. 43-47

[18] S. A. Voitkevich, Essential oils for perfumes and aromatherapy, M.: Food Industry, 1999, pp. 284

[19] N. I. Bochkarev, E. V. Zelentsov Soshnenko, Morphology, taxonomy, selection methods and characteristics of Coriandrum sativumvarieties (review), Oil Crops. Research and Technical Bulletin of the AllRussian Research Institute of Oil Crops, 2(159-160), 2014, pp. 178-195

[20] V. D. Rabotyagov, A. E. Palyi, O. N. Kurdyukova, Essential Oils of Aromatic Plants: Monograph. Simferopol: ARIAL Printing and Publishing House, 2017, pp. 29-30

[21] G. Burdock, I. G. Carabin, Safety assessment of coriander (Coriandrum sativum L.) essential oil as a food ingredient, Food and Chemical Toxicology, 47(1), 2009, pp. 22-34 doi: 10.1016/j.fct.2008.11.006

[22] K. L. Lvov, P. A. Zakhrebetkov, L. V. V. D. Luzina, Vodolagin, L. V. Volontsevich, Coriander, M.-L.: Pishchepromizdat 1937, pp. 56

[23] L. A. Radchenko, A. V. Prikhodko, A. V. Demchuk, A. F. Radchenko, E. V. Remeslo, Yu. N. Kostanchuk, V. I. Nemtinov, N. A. Eliseeva, P. S. Ostapchuk, S. A. Emelyanov, A. V. Pashtetskaya, A. V. Mishnev, N. V. Nevkritaya, Scientifically based development strategy for the agro-industrial complex of Crimea until 2020. Crop production and livestock farming, Research Institute of Agriculture of Crimea, Under the general editorship of V.S. Pashtetsky, Simferopol, 2016, pp. 78-79

[24] M. V. Verdysh, A. A. Popova, Influence of world market on the parameters of coriander growing in the Russian
Federation, In the book: Current status, problems and prospects for the development of agricultural science. Materials of the IV International Research and Practical Conference, Science editor V.S. Pashtetsky, 2019, pp. 332333. doi: 10.33952 / 09/09/2019.168

[25] S. S. Babanina, L. S. Memisheva, N. S. Babanov, G. D. Kravchenko, Development of structural elements of coriander productivity depending on meteorological conditions. Oil Crops. Research and Technical Bulletin of the All-Russian Research Institute of Oil Crops, 2(170), 2017, 70-75

[26] L. P. Zbrailova, E. V. Kartamysheva, T. N. Luchkina, A. S. Bushnev, Assessment and selection of coriander source material for developing new varieties for the zone of insufficient precipitation in the Rostov Region, Grain Farming of Russia, 5(65), 2019, pp. 55-61 doi: 10.31367 / 2079-8725-2019-65-5-55-61

[27] S. G. Milner, M. Jost, S. Taketa, et al; G. Herren, T. Müller, S. G. Krattinger, B. Keller, Genebank genomics highlights the diversity of a global barley collection. Nature Genetics, 51(2), 2019, pp. 319-326 DOI: doi.org/10.1038/s41588-018-0266-X

[28] R. Galek, E. Sawicka-Sienkiewicz, D. Zalewski, S. Stawinski and K. Spychala, Searching for Low Alkaloid Forms in the Andean Lupin (Lupinus mutabilis) Collection. Czech J. Genet. Plant Breed, 53(2), 2017, pp. 55-62 doi: 10.17221/71/2016-CJGPB

[29] K. Jyothi, R. Purnima Mishra, M. Sujatha, V. Joshi, Genetic Variability, Heritabilty and Genetic Advance for Yield and Its Component in Indigenous Collection of Coriander (Coriandrum sativum L.) Germplasm. Int. J. Pure App. Biosci, 5(3), 2017, pp. 301-305 doi:10.18782/2320-7051.5013

[30] A. R. Devi, A. B. Sharangi, M. C. Haokip, Genetic variability studies of coriander (Coriandrum sativum L.) genotypes. Journal of Pharmacognosy and Phytochemistry, 8(4), 2019, pp. 419-421

[31] D. Punetha, G. Tewari, C. Pande, Compositional variability in inflorescence essential oil of Coriandrum sativum from North India. Journal of Essential Oil

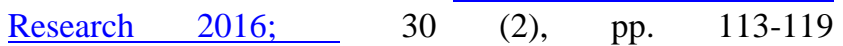
doi:10.1080/10412905.2017.1399169

[32] V. S. Pashtetsky, N. V. Nevkritaya, A. V. Mishnev, L.G. Nazarenko, Essential oil industry in Crimea. Yesterday, Today, Tomorrow. $2^{\text {nd }}$ edition, revised. Simferopol: ARIAL Printing and Publishing House 2018, pp. 320

[33] L. G. Romanenko, N. V. Nevkritaya, L. N. Serkov, Ways to create resistance of coriander source material to ramulariosis, Selection and Seed Production, 1985, pp. 31

[34] L. P. Savchuk, Climate of Crimean foothills and essential-oil-bearing plants. Simferopol, 2006, pp. 76

[35] I. N. Beydeman, Methodology for studying the phenology of plants and phytocoenoses, M.: Nauka 1974, pp. 280

[36] Selection of essential oil crops (guidelines), ed. by A.I. Arinstein. Simferopol: All-Union Research Institute of Essential Oil Crops, 1977, pp. 150 
[37] Biochemical methods for the analysis of essential oil plants and essential oils: collection of scientific papers. Simferopol: All-Union Research Institute of Essential Oil Crops, 1972, pp. 107

[38] B. A. Dospekhov, Methodology for field trials (with the basics of statistical processing of research results), M.: Kniga po trebovaniyu, 2012, pp. 352

[39] G. F. Lakin, Biometrics, M.: Vysshaya shkola, 1990, pp. 350

[40] V. S. Pashtetskiy, N. V. Nevkrytaya, A. V. Mishnev, History, modern state and prospects of the essential oil industry development, Agrarian bulletin of the Urals, 11 (165), 2017, pp. 37-46
Creative Commons Attribution License 4.0 (Attribution 4.0 International, CC BY 4.0)

This article is published under the terms of the Creative Commons Attribution License 4.0

https://creativecommons.org/licenses/by/4.0/deed.en_US 